\title{
Anticipating One's Troubles: The Costs and Benefits of Negative Expectations
}

\section{Citation}

Golub, Sarit A., Daniel T. Gilbert, and Timothy D. Wilson. 2009. Anticipating one's troubles: the costs and benefits of negative expectations. Emotion 9(2): 277-281.

\section{Published Version}

http://dx.doi.org/10.1037/a0014716

\section{Permanent link}

http://nrs.harvard.edu/urn-3:HUL.InstRepos:3119461

\section{Terms of Use}

This article was downloaded from Harvard University's DASH repository, and is made available under the terms and conditions applicable to Other Posted Material, as set forth at http:// nrs.harvard.edu/urn-3:HUL.InstRepos:dash.current.terms-of-use\#LAA

\section{Share Your Story}

The Harvard community has made this article openly available.

Please share how this access benefits you. Submit a story.

Accessibility 


\title{
Anticipating One's Troubles: The Costs and Benefits of Negative Expectations
}

\author{
Sarit A. Golub \\ Hunter College, CUNY
}

\author{
Daniel T. Gilbert \\ Harvard University
}

\author{
Timothy D. Wilson \\ University of Virginia
}

\begin{abstract}
Although negative expectations may have the benefit of softening the blow when a negative event occurs, they also have the cost of making people feel worse while they are waiting for that event to happen. Three studies suggest that the cost of negative expectations is greater than the benefit. In 2 laboratory experiments and a field study, people felt worse when they were expecting a negative than a positive event; but once the event occurred, their prior expectations had no measurable influence on how they felt. These results suggest that anticipating one's troubles may be a poor strategy for maximizing positive affect.
\end{abstract}

Keywords: affective forecasting, pessimism, expectations

It is tragic for the soul to be apprehensive of the future and wretched in anticipation of wretchedness. What madness it is to anticipate one's troubles!

—Lucius Annaeus Seneca (4 BC-65 AD; 1925)

Is it really madness to anticipate one's troubles? Seneca (1925) argued that the cost of anticipating a negative event is that it produces an unpleasant state of dread ("I expect her to say no when I ask her out and I feel bad just thinking about it"). However, he failed to mention the benefits, namely, that anticipating a negative event leads to affective attenuation when the event turns out badly ("I always knew she'd say no, so I'm not that disappointed") and affective amplification when it turns out well ("I thought she'd say no-so I'm absolutely delighted that she said yes!"). The anticipation of positive events has precisely the opposite set of costs and benefits. Anticipating a positive event produces a pleasant state of savoring ("I expect him to say yes when I ask him out, and I feel good just thinking about it"), but it also produces affective attenuation when the event turns out well ("I always knew he'd say yes, so I'm not that excited") and affective amplification when it turns out badly ("I thought he'd say yes-so I'm terribly disappointed!"). In short, as Table 1 shows, the anticipation of future

Sarit A. Golub, Department of Psychology, Hunter College, CUNY; Daniel T. Gilbert, Department of Psychology, Harvard University; Timothy D. Wilson, Department of Psychology, University of Virginia.

We acknowledge support of research Grant BCS-0722132 from the National Science Foundation to Daniel T. Gilbert and Timothy D. Wilson. We thank David Canose, Dominic Hood, and Chris Soutter for their help with the execution of these experiments, and James Shepperd and Jonathan Brown for their comments on the manuscript.

Correspondence concerning this article should be addressed to Daniel Gilbert, Department of Psychology, William James Hall, 33 Kirkland Street, Harvard University, Cambridge, MA 02138. E-mail: gilbert@ wjh.harvard.edu events has pre-event affective consequences (Berns et al., 2006; Elster \& Loewenstein, 1992; Lovallo \& Kahneman, 2000), but it also has postevent affective consequences of the opposite valence (Feather, 1969; Kahneman \& Miller, 1986; Mellers, Schwartz, \& Ritov, 1999; Shepperd \& McNulty, 2002).

How likely are these pre-event and postevent consequences to accrue? Although people think of amplification and attenuation as common phenomena, research suggests that they occur under limited circumstances. For example, amplification and attenuation are typically observed in studies that measure affect immediately after an event occurs. People who are given a series of gustatory rewards every few seconds show greater activation in brain regions associated with subjective pleasure when they cannot predict the value of the reward on each trial (Berns, McClure, Pagnoni, \& Montague, 2001), and people who engage in a series of brief gambles or perform a series of brief tasks report more intense affective responses on trails on which they receive unexpected outcomes (McGraw, Mellers, \& Ritov, 2004; Mellers, Schwartz, Ho, \& Ritov, 1997). Amplification and attenuation are also commonly observed in studies that measure postevent affect after people are explicitly reminded of their prior expectations (Shepperd \& McNulty, 2002).

On the other hand, studies in which people report their affect after a short delay and/or are not reminded of their prior expectations typically provide little evidence of either amplification or attenuation. Although many studies report positive correlations between (a) people's affective reactions, and (b) the discrepancy between their predicted and actual outcomes, Marshall and Brown (2006) demonstrated that this approach is susceptible to statistical artifact. Evidence for amplification and attenuation in these situations requires an analytic approach that independently estimates the affective consequences of events and expectancies, and Marshall and Brown reported that "in our search of the literature we could not find one study that used this analytic approach" (p. 45). 
Table 1

Costs and Benefits of Expectations

\begin{tabular}{cll}
\hline & \multicolumn{2}{c}{ Expectation } \\
\cline { 2 - 3 } Event & \multicolumn{1}{c}{ Positive } & \multicolumn{1}{c}{ Negative } \\
\hline Positive & Pre-event benefit $=$ Savoring & Pre-event cost $=$ Dread \\
& Postevent cost $=$ Attenuation & Postevent benefit = Amplification \\
Negative & Pre-event benefit $=$ Savoring & Pre-event cost $=$ Dread \\
& Postevent cost $=$ Amplification & Postevent benefit = Attenuation \\
\hline
\end{tabular}

They concluded that there is little evidence for either amplification or attenuation.

We believe that when taken as a whole, the literature suggests that amplification and attenuation do occur immediately after an event when an expectation is active in memory and the discrepancy between it and the event is particularly salient, but that these postevent consequences quickly dissipate as the event begins to command the person's attention and the expectation begins to fade from awareness (Novemsky \& Ratner, 2003). This claim has important implications. The novelist Thomas Hardy suggested that holding negative expectations of the future was a "sure game. You cannot lose at it; you may gain. It is the only view of life in which you can never be disappointed" (Pearce, 2002, p. 40). According to Hardy, negative expectations are always beneficial because they amplify positive affect and attenuate negative affect, and people do seem to "brace for the worst" in the hope of attenuating negative affective responses or amplifying positive affective responses to an imminent event (Shepperd, Ouellette, \& Fernandez, 1996; Taylor \& Sheppard, 1998). Alas, the scientific literature suggests that there are at least two problems with this strategy. First, as the research described above suggests, negative expectations may not provide the benefits of amplification or attenuation in many or even most circumstances. Second, this strategy ignores the fact that negative expectations have costs in the pre-event periodnamely, people who are expecting the worse feel bad while they are doing so. If the costs of negative expectations are common and easily produced while the benefits are not, then the sure game may be a sucker's bet.

In three studies, we sought to determine whether negative expectations produce postevent benefits that justify their pre-event costs. In Studies 1a and 1b, we measured the costs and benefits of negative expectations in a laboratory experiment, and in Study 2 we measured them in a field setting. We expected to find that the pre-event costs of negative expectations would be more readily observed than the postevent benefits.

\section{Studies $1 \mathrm{a}$ and $1 \mathrm{~b}$}

In Studies 1a and 1b, participants completed a personality assessment and waited for $10 \mathrm{~min}$ before receiving their results. During this waiting period, participants were led to have positive, negative, or no expectations about the results. Participants reported their affective states during the waiting period. Participants were then told that the results were negative (Study 1a) or positive (Study 1b) and then reported their affective states again.

\section{Method}

Participants in Study 1a were 36 Harvard undergraduates (20 women and 16 men), and participants in Study 1b were 39 Harvard undergraduates (22 women and $17 \mathrm{men}$ ). All participants received either $\$ 5$ or course credit for their participation.

Participants were told that they would be taking a computerized personality test and would be classified as one of three types (A, $\mathrm{B}$, or C). Participants read a brief description of each type and learned that A was the best, B was intermediate, and C was the worst. These descriptions had been used in previous studies (Gilbert, Lieberman, Morewedge, \& Wilson, 2004; Gilbert, Pinel, Wilson, Blumberg, \& Wheatley, 1998). Participants were told that the test was reliable and valid when scored by a psychologist, but that because this was so expensive and time consuming the experimenter was hoping to develop computer software that could quickly and cheaply predict a psychologist's classification. The experimenter explained that participants' tests would be scored by a psychologist who was in another room and that while this was occurring an experimental computer program would analyze their answers and attempt to predict the psychologist's classification.

All participants answered 18 ambiguous questions on a computer (e.g., "What two adjectives would you use to describe your closest friend?" and "If you could wake up tomorrow having gained one new ability or quality, what would it be?"). When participants were finished, their answers were ostensibly submitted to both the experimental computer program and the psychologist. Participants were then randomly assigned to the positive expectation, negative expectation, or no expectation condition. Participants in the positive and negative expectation conditions were told that while they were waiting for the psychologist to classify them they could press a key to see the computer's prediction of the psychologist's classification. Participants were reminded that the computer program was not always accurate in predicting a psychologist's classification, but that it would probably give them "a sense of what to expect." When participants pressed the key, the computer listed the probabilities that participants in the positive expectation condition would be classified as an A, B, or C as $91 \%$, $9 \%$, and $1 \%$, respectively, and that participants in the negative expectation condition would be classified as an $\mathrm{A}, \mathrm{B}$, or $\mathrm{C}$ as $1 \%$, $9 \%$, and $91 \%$, respectively. Participants in the no expectation condition were not given an opportunity to view the computer's predictions.

Five minutes after pressing the key, the experimenter asked participants to indicate how happy and how disappointed they felt by marking a pair of 12-cm linear analog scales that were anchored at the end points with the phrases not at all and extremely. Five 
minutes after completing these measures, the experimenter told each participant that he or she had been classified by the psychologist as a Type C (Study 1a) or as a Type A (Study 1b). Two minutes after receiving this information, the experimenter asked participants to complete the same scales they had completed earlier. Thus, the order of events was as follows: Expectation $\rightarrow$ 5 -min delay $\rightarrow$ pre-event report $\rightarrow$-min delay $\rightarrow$ event $\rightarrow$ 2-min delay $\rightarrow$ postevent report. It is worth noting that by measuring pre-event affect $5 \mathrm{~min}$ before the event but measuring postevent affect 2 min after the event we stacked the deck in favor of finding greater postevent than pre-event effects (which was the opposite of what we expected to find).

\section{Study la Results}

Participants in Study 1a were given negative feedback. Participants' happiness and disappointment scores were negatively correlated in the pre-event period $(r=-.56, p<.001)$ and the postresults period $(\mathrm{r}=-.42, p=.01)$, and thus we created a pre-event positive affect index and a postevent positive affect index by subtracting participants' reports of disappointment from their reports of happiness. These indexes were submitted to a 2 (period: pre-event or postevent) by 3 (expectation: positive, negative, none) repeated measures analysis of variance (ANOVA), which revealed a Period $\times$ Expectation interaction, $F(2,33)=$ 5.45, $p<.01$. As Table 2 shows, participants felt worse $5 \mathrm{~min}$ before the event when they had negative rather than positive expectations, $t(24)=3.91, p=.001$, but participants who had negative and positive expectations felt equally bad $2 \mathrm{~min}$ after the event, $t(24)<1$. In short, negative expectations had pre-event costs but no postevent benefits.

Table 2

Affect Index in Studies $1 a$ and $1 b$

\begin{tabular}{ccc}
\hline Expectation & Pre-event period & Postevent period \\
\hline Negative event (Study 1a) & & \\
Positive $(n=13)$ & & \\
$M$ & $5.97_{\mathrm{b}}$ & $2.34_{\mathrm{c}}$ \\
$S D$ & 2.37 & 4.74 \\
None $(n=10)$ & $2.98_{\mathrm{a}}$ & $-1.11_{\mathrm{c}}$ \\
$M$ & 4.30 & 3.64 \\
$S D$ & & \\
Negative $(n=13)$ & $0.24_{\mathrm{a}}$ & $0.95_{\mathrm{c}}$ \\
$M$ & 4.73 & 4.79 \\
$S D$ & & \\
Positive event (Study 1b) & & $3.90_{\mathrm{c}}$ \\
Positive $(n=13)$ & $3.82_{\mathrm{a}}$ & 3.64 \\
$M$ & 3.62 & $4.79_{\mathrm{c}}$ \\
$S D$ & & 3.35 \\
None $(n=12)$ & $4.04_{\mathrm{a}}$ & \\
$M$ & 3.12 & $3.70_{\mathrm{c}}$ \\
$S D$ & & \\
Negative $(n=14)$ & $0.10_{\mathrm{b}}$ & \\
$M$ & 4.67 & \\
$S D$ & &
\end{tabular}

Note. Means represent affect indexes that range from -12 (not at all happy and extremely disappointed) to 12 (extremely happy and not at all disappointed). Within columns, means with different subscripts differ at $p<.05$.

\section{Study $1 b$ Results}

Participants in Study 1b were given positive feedback. Participants' happiness and disappointment scores were negatively correlated in the pre-event period $(r=-.71, p<.001)$ and the postevent period $(\mathrm{r}=-.56, p<.001)$, and thus we created a pre-event positive affect index and a postevent positive affect index as in Study 1a. These indexes were submitted to a 2 (period: pre-event or postevent) by 3 (expectation: positive, negative, none) repeated measures ANOVA, which revealed a Period $\times$ Expectation interaction, $F(2,33)=5.45, p<.01$. As Table 2 shows, participants felt better $5 \mathrm{~min}$ before the event when they had positive rather than negative expectations, $t(25)=2.30, p=.03$, but participants who had positive and negative expectations felt equally good $2 \mathrm{~min}$ after the event, $t(25)<1$. In short, positive expectations had pre-event benefits and no postevent costs. ${ }^{1}$

\section{Study 2}

In Study 2 we sought to determine whether the pattern of results we observed in the laboratory-namely, pre-event consequences without postevent consequences-would also be observed in a common field setting.

\section{Method}

Participants were 138 Harvard undergraduates (70 men and 68 women) in an introductory psychology course who participated for course credit. Participants received a questionnaire by email about $48 \mathrm{hr}$ after taking their midterm exam and about $72 \mathrm{hr}$ before receiving their scores. This pre-event measure asked them to predict their score on the exam by completing three items: (a) "How worried are you about your grade on the exam?", based on a 7-point scale ranging from 1 (not at all worried) to 7 (extremely worried); (b) "How do you think you did on the exam?", based on a 7-point scale ranging from 1 (extremely well) to 7 (extremely poor); and (c) "How do you think your performance on the exam will compare to other students?", based on a 7-point scale ranging from 1 (much worse) to 7 (much better). The pre-event measure also asked participants to complete the Positive and Negative Affect Scale (PANAS; Watson, Clark, \& Tellegen, 1988). Participants received a second questionnaire by email about $24 \mathrm{hr}$ after receiving their grade on the exam. This postevent measure asked them to complete the PANAS. Participants' responses were coded with an encrypted identifier that allowed their responses to be linked to their exam grades.

\section{Results}

Of the 138 participants who completed the pre-event measure, 53 male and 60 female participants $(82 \%)$ also completed the postevent measure. The three items on the pre-event measure that measured participants' expectations about their exam scores were

\footnotetext{
${ }^{1}$ Statistical power in Studies $1 \mathrm{a}$ and $1 \mathrm{~b}$ was low, and the results of these studies should not be taken to mean that expectations cannot have postevent effects. Rather, they should be taken to mean that at any given level of statistical power, pre-event effects are stronger and thus easier to detect than are postevent effects.
} 
highly correlated $(\alpha=.83)$ and thus we averaged them to create an expectation index. Both the pre-event measure and the postevent measure included the PANAS. Both the positive and negative affect subscales of the PANAS were internally consistent in both the pre-event and postevent periods (all $\alpha \geq .87$ ). We created a pre-event affect index and a postevent affect index by subtracting the sum of the negative PANAS items from the sum of the positive PANAS items.

The correlation between the expectation index and the affect index from the pre-event period was $r=.44, p=.001$. The more negative students' expectations were, the worse they felt in the pre-event period. The postevent affect index was used as the dependent measure in a hierarchical regression, with participants' exam scores entered first and the expectation index entered second. This approach was designed to estimate attenuation/amplification effects independent of (i.e., after controlling for) event effects. If negative expectations confer benefits to participants who received low scores (attenuation) as well as those who received high scores (amplification), then negative expectations should be associated with more positive postevent affect for all participants, regardless of the grade they received. As Table 3 shows, participants who scored well on the exam felt better after receiving their grade than did participants who scored poorly. However, after controlling for the score they received, participants' expectations about those scores were unrelated to their affective states in the postevent period. In short, participants with positive expectations felt better 3 days before receiving their grades but did not feel worse a day after actually receiving them, whereas participants with negative expectations felt worse 3 days before receiving their grades but did not feel better a day after receiving them.

\section{General Discussion}

In three studies, expectations had affective consequences in the pre-event period but not in the postevent period. Before receiving personality feedback, participants who had negative expectations were less happy than participants who had positive expectations; but after receiving feedback, participants who had had negative expectations were no happier than participants who had had positive expectations. Before receiving their grades, students who had negative expectations were less happy than students who had positive expectations; but after receiving their grades, students who had had negative expectations were no happier than students who had had positive expectations. In other words, expectations about an event mattered until the event happened, at which time

Table 3

Summary of Hierarchical Regression Analysis in Study 2

\begin{tabular}{lccc}
\hline \multicolumn{1}{c}{ Variable } & B & SE B & $\beta$ \\
\hline $\begin{array}{l}\text { Step 1 } \\
\quad \text { Exam grade }\end{array}$ & 0.69 & .21 & $.30^{* * *}$ \\
$\begin{array}{l}\text { Step 2 } \\
\quad \text { Exam grade } \\
\quad \begin{array}{l}\text { Expectation during pre-event } \\
\quad \text { period }\end{array}\end{array}$ & 0.58 & .22 & $.25^{*}$ \\
\hline
\end{tabular}

${ }^{\mathrm{a}} R^{2}=.09$ for Step $1(p=.001) ; \Delta R^{2}=.02$ for Step $2(p=.11)$.

${ }^{*} p<.01$. ${ }^{* * *} p<.001$. the event - and not people's prior expectations about it—-became the determinant of their affective states. Although expecting the worst can sometimes make people feel better in the postevent period (Mellers et al., 1997) and can sometimes induce them to work harder in the pre-event period (Norem \& Cantor, 1986), our studies suggest that the affective benefits of negative expectations may be more elusive than their costs.

If negative expectations do little to attenuate the affective consequences of receiving a poor exam score or unflattering personality feedback, then why do most people seem to have compelling intuitions to the contrary (Shepperd \& McNulty, 2002)? One reason may be that expectations are most likely to have postevent consequences in the early moments of the postevent period (Berns et al., 2001; McGraw et al., 2004; Mellers et al., 1997; Shepperd $\&$ McNulty, 2002), and research has shown that when people think about events that extend over time, they tend to think about the events' early moments (Gilbert \& Wilson, 2007; Kahneman, 1999). For example, when people are asked to imagine being paraplegic they tend to imagine becoming paraplegic, and because paraplegia is surely worse on the first day than the one-thousandth day, people typically overestimate how bad that state would be (Brickman, Coates, \& Janoff-Bulman, 1978; Gilbert et al., 1998; Riis et al., 2005; Ubel et al., 2001). It may be that when students imagine how they will feel if they receive a bad grade on a test, they imagine getting the bad grade rather than having the bad grade-in other words, they imagine the opening moment of the postevent period in which their negative expectations are most likely to have affective consequences rather than the more numerous moments that follow in which their expectations may have no effect whatsoever. Expectations may have only brief consequences, but because people who are thinking about a future event tend to imagine the very moments in which such consequences are most likely to be realized, they may overestimate the benefitsand underestimate the costs - of expecting the worst. It may be that as Seneca (1925) noted nearly 2 millennia ago, "He who suffers before it is necessary suffers more than is necessary" (p. 123).

\section{References}

Berns, G. S., Chappelow, J., Cekic, M., Zink, C. F., Pagnoni, G., \& Martin-Skurski, M. E. (2006). Neurobiological substrates of dread. Science, 312, 754-758.

Berns, G. S., McClure, S. M., Pagnoni, G., \& Montague, P. R. (2001). Predictability modulates human brain response to reward. The Journal of Neuroscience, 21, 2793-2798.

Brickman, P., Coates, D., \& Janoff-Bulman, R. J. (1978). Lottery winners and accident victims: Is happiness relative? Journal of Personality and Social Psychology, 36, 917-927.

Elster, J., \& Loewenstein, G. (1992). Utility from memory and anticipation. In G. Loewenstein \& J. Elster (Eds.), Choice over time (pp. 213-234). New York: Sage Foundation.

Feather, N. T. (1969). Attribution of responsibility and valence of success and failure in relation to initial confidence and task performance. Journal of Personality and Social Psychology, 13, 129-144.

Gilbert, D. T., Lieberman, M. D., Morewedge, C. K., \& Wilson, T. D. (2004). The peculiar longevity of things not so bad. Psychological Science, 15, 14-19.

Gilbert, D. T., Pinel, E. C., Wilson, T. D., Blumberg, S. J., \& Wheatley, T. P. (1998). Immune neglect: A source of durability bias in affective forecasting. Journal of Personality and Social Psychology, 75, 617-638. 
Gilbert, D. T., \& Wilson, T. D. (2007). Prospection: Experiencing the future. Science, 317, 1351-1354.

Kahneman, D. (1999). Objective happiness. In D. Kahneman, E. Diener, \& N. Schwarz (Eds.), Well-being: The foundations of hedonic psychology (pp. 3-25). New York: Sage Foundation.

Kahneman, D., \& Miller, D. T. (1986). Norm theory: Comparing reality to its alternatives. Psychology Review, 93, 136-153.

Lovallo, D., \& Kahneman, D. (2000). Living with uncertainty: Attractiveness and resolution timing. Journal of Behavioral Decision Making, 13, 179-190.

Marshall, M. A., \& Brown, J. D. (2006). Emotional reactions to achievement outcomes: Is it really best to expect the worst? Cognition and Emotion, 20, 43-63.

McGraw, A. P., Mellers, B. A., \& Ritov, I. (2004). The affective costs of overconfidence. Journal of Behavioral Decision Making, 17, 281-295.

Mellers, B. A., Schwartz, A., Ho, K., \& Ritov, I. (1997). Decision affect theory: Emotional reactions to the outcomes of risky options. Psychological Science, 8, 423-429.

Mellers, B. A., Schwartz, A., \& Ritov, I. (1999). Emotion-based choice. Journal of Experimental Psychology: General, 128, 332-345.

Norem, J. K., \& Cantor, N. (1986). Defensive pessimism: Harnessing anxiety as motivation. Journal of Personality and Social Psychology, 51, $1208-1217$.

Novemsky, N., \& Ratner, R. K. (2003). The time course and impact of consumers' erroneous beliefs about hedonic contrast effects. Journal of Consumer Research, 29, 507-516.

Pearce, R. (2002). Sayings of Thomas Hardy. New York: Duckworth.
Riis, J., Loewenstein, G., Baron, J., Jepson, C., Fagerlin, A., \& Ubel, P. A. (2005). Ignorance of hedonic adaptation to hemo-dialysis: A study using ecological momentary assessment. Journal of Experimental Psychology: General, 134, 3-9.

Seneca, L. A. (1925). Moral epistles (R. M. Gummere, Trans.; Vol. 3). Cambridge, MA: Harvard University Press.

Shepperd, J. A., \& McNulty, J. K. (2002). The affective consequences of expected and unexpected outcomes. Psychological Science, 13, 85-88.

Shepperd, J. A., Ouellette, J. A., \& Fernandez, J. K. (1996). Abandoning unrealistic optimism: Performance estimates and the temporal proximity of self-relevant feedback. Journal of Personality and Social Psychology, $70,844-855$.

Taylor, K. M., \& Sheppard, J. A. (1998). Bracing for the worst: Severity, testing, and feedback timing as moderators of the optimistic bias. Personality and Social Psychology Bulletin, 9, 915-926.

Ubel, P. A., Loewenstein, G., Hershey, J., Baron, J., Mohr, T., Asch, D. A., et al. (2001). Do nonpatients underestimate the quality of life associated with chronic health conditions because of a focusing illusion? Medical Decision Making, 21(3), 190-199.

Watson, D., Clark, A. L., \& Tellegen, A. (1988). Development and validation of brief measures of positive and negative affect: The PANAS scales. Journal of Personality and Social Psychology, 54, 1063-1070.

Received November 1, 2007

Revision received July 21, 2008

Accepted October 31, 2008

\section{Members of Underrepresented Groups: Reviewers for Journal Manuscripts Wanted}

If you are interested in reviewing manuscripts for APA journals, the APA Publications and Communications Board would like to invite your participation. Manuscript reviewers are vital to the publications process. As a reviewer, you would gain valuable experience in publishing. The P\&C Board is particularly interested in encouraging members of underrepresented groups to participate more in this process.

If you are interested in reviewing manuscripts, please write APA Journals at Reviewers@apa.org. Please note the following important points:

- To be selected as a reviewer, you must have published articles in peer-reviewed journals. The experience of publishing provides a reviewer with the basis for preparing a thorough, objective review.

- To be selected, it is critical to be a regular reader of the five to six empirical journals that are most central to the area or journal for which you would like to review. Current knowledge of recently published research provides a reviewer with the knowledge base to evaluate a new submission within the context of existing research.

- To select the appropriate reviewers for each manuscript, the editor needs detailed information. Please include with your letter your vita. In the letter, please identify which APA journal(s) you are interested in, and describe your area of expertise. Be as specific as possible. For example, "social psychology" is not sufficient-you would need to specify "social cognition" or "attitude change" as well.

- Reviewing a manuscript takes time (1-4 hours per manuscript reviewed). If you are selected to review a manuscript, be prepared to invest the necessary time to evaluate the manuscript thoroughly. 